\title{
Results of a support programme for treatment of overweight and obese patients with orlistat
}

\author{
K. Kobbevik', U. Gisletun', F. Hansson ${ }^{2}$ and S. Tonstad ${ }^{3}$ \\ 'Roche Norge AS, Oslo, Norway ${ }^{2}$ Planteringsv I I, Furulund, Sweden ${ }^{3}$ Department of Preventive Cardiology, Ullevål \\ University Hospital, Oslo, Norway
}

Abstract

Background: Overweight and obesity are reaching epidemic proportions, and a variety of therapeutic countermeasures is needed. This article describes a support programme for orlistat.

Methods: Physicians who prescribed orlistat could refer their patients to a support programme provided by the manufacturer. A clinical nutritionist evaluated the patient's diet and gave advice and motivational support during approximately seven telephone consultations a year.

Design: A cohort study.

Results: Of 3526 patients $(81.5 \%$ women and $18.5 \%$ men) whose first contact with the nutritionist was recorded between April 2001 and July 2004, 3023 had at least one follow-up consultation. The mean initial body mass index (BMI) was 33.7 (SD 9.0). Of men and women, 90\% and 80\%, respectively, met the Norwegian Pharmaceutical Product Compendium criteria for orlistat. The remaining patients had a BMI that was too low or no reported risk factors. Of the 2456 patients who reported their weight at two or more consultations, $70 \%$ achieved a $\geq 5 \%$ weight loss. Patients who took part in the programme for 4.5 months or more, and reported their weight at two or more consultations $(n=1891,62.5 \%)$, had a mean weight reduction of $9.1 \%(95 \%$ confidence interval 7.8 to $10.4 \%)$ of the initial weight.

Conclusion: The combination of telephone advice provided by a clinical nutritionist and orlistat had a clinically significant effect among over two-thirds of patients who reported their weight. Use of orlistat largely followed medical recommendations with regard to the target population.

Keywords: cardiovascular risk factors; dietary therapy; nutritionist, obesity; orlistat; overweight; support programme

Received: 3 Jun. 2005; Revised 22 Jul. 2005; Accepted: 3 Aug. 2005

\section{Introduction}

Body weight is increasing in all age groups of the Norwegian population (1). This increase in weight necessitates preventive and therapeutic countermeasures at several levels, including societal and individual ones (1).

A relatively moderate loss of weight, i.e. $5-10 \%$ of the original weight, may result in improved health and lower morbidity even if the body weight does not reach the normal level. There is widespread agreement that this reduction in weight should be the treatment target because it provides most of the health benefits, including improved lipids, reduced blood pressure, reduced risk of developing type 2 diabetes, and lower fasting blood glucose in those who have already developed type 2 diabetes (1-3).
The dietary habits of overweight and obese patients may be modified by nutritionist-based advice, and an extensive body of experience has underscored that follow-up during the weightreduction phase increases the chances of success (4-6). Obesity medication may effectively supplement diet and lifestyle changes. Orlistat is a lipase inhibitor acting locally in the small intestine and reducing the uptake of fat from the diet by about $30 \%(3,7)$. The medication has been approved for treatment of obese individuals with a body mass index (BMI) $\geq 30$ or those overweight individuals with a BMI $\geq 28$ with other additional risk factors. Adverse effects are mainly related to inhibition of fat absorption and subsequent gastrointestinal symptoms if the fat intake is too high. One year 
after launching orlistat in Norway in March 2000, the manufacturer (Roche) introduced a follow-up programme for patients given orlistat by their physicians. The main aims of this study were to see whether patients using orlistat in clinical practice outside a controlled trial met the recommended medical criteria for the use of the medication and whether these patients achieved weight loss. The length of adherence to the programme was also examined.

\section{Methods}

Patients in this study who received a prescription for orlistat were offered a referral card for free followup by a clinical nutritionist employed by the manufacturer. The referral card was issued by the doctor, at the pharmacist or printed out from the Internet (www.lettereliv.no). This card provided information about the service and an opportunity to indicate a suitable time when the patient could be contacted. The cards that were received were followed up by written information stating that a nutritionist would telephone within 2 weeks. If the nutritionist failed to make contact with the patient, at least four new attempts were made. If contact had still not been made, the nutritionist sent a letter encouraging the patient to return an enclosed card with information about a new possible time for making contact. The follow-up started with the first telephone contact. This consultation was estimated to last for about $20 \mathrm{~min}$. After this, six follow-up consultations were planned in the course of 1 year. The follow-up consultations were estimated to last for about $10 \mathrm{~min}$. Further consultations were offered for as long as the patient was taking orlistat. The service was available on weekdays from 09.00 to $19.00 \mathrm{~h}$. The patients were also able to call the nutritionist at a free telephone number between the agreed consultations. Patients could stop the programme at any time they chose.

Dietary advice was given according to the patient-centred clinical method (8). The nutritionist treated the patient as an equal, taking the patient's thoughts, feelings and expectations into account. During the first telephone consultation, the patient was asked about age, height, weight at the start of treatment, earlier attempts to lose weight, present weight, target of treatment, date of starting to take orlistat, number of capsules taken per day, possible side-effects of using orlistat, physical activity, and whether the patient had other diseases or complications of overweight or obesity such as type 2 diabetes, high cholesterol or high blood pressure (only after November 2002). All data were selfreported. The patient's diet was evaluated using the diet history method (9). If the nutritionist and/or the patient considered that the diet history did not provide an adequate picture of the diet, the patient was asked to perform a 4 day written record of the diet using kitchen scales (9).

After discussing the patient's dietary habits and lifestyle, the nutritionist and the patient agreed on concrete targets regarding diet, physical activity and/or weight. The nutritionist helped the patient to agree on realistic targets for both the size of the weight reduction and the changes in diet and exercise habits. As well as personal advice via the telephone, the patient was given written information (Table 1) including recommendations for diet and physical activity, recipes and ideas based on the recommendations from the Nutrition Department of the Directorate for Health and Social Affairs (10). At each follow-up consultation the patient was asked about his or her weight, diet, exercise and possible side-effects of orlistat, and the nutritionist based subsequent advice on her evaluation of the weight and dietary changes, and exercise habits. The evaluation of the diet was done either by using a diet history, or by asking the patient to record all food and drinks consumed for 4 days using kitchen scales. Motivation and encouragement were also a large part of the follow-up consultations.

In general, the dietary recommendations from the Nutrition Department of the Directorate for Health and Social Affairs (10) were followed, although with a slightly higher percentage of energy from protein. The patient was advised to:

- eat three main meals and a couple of small, nonfat snacks distributed throughout the day

- be aware of the type and amount of fat

- choose low-fat meat and dairy products

- eat fatty fish at least a couple of times a week or take supplementary cod-liver or fish oil

- choose wholemeal cereal products

- eat large amounts of fruit, berries and vegetables

- reduce refined sugar.

The energy distribution in the recommended diet was $<30$ energy per cent $(E \%)$ from fat, of which $<10 E \%$ was from saturated fat and trans fat, and the remainder from unsaturated fat, $15-20 E \%$ 
Table I. Written information

\begin{tabular}{|c|c|}
\hline Name of brochure & Contents of brochure \\
\hline A good start ${ }^{\mathrm{a}}$ & $\begin{array}{l}\text { A summary of the most important advice from all the material, and a diagram for entering weight, waist } \\
\text { circumference and results of laboratory tests }\end{array}$ \\
\hline Dietary advice to those taking Xenical ${ }^{\mathrm{a}}$ & Advice on diet and activity, with more details than "A good start" \\
\hline Correct fat ${ }^{\mathrm{a}}$ & Sources of healthy and unhealthy fat \\
\hline Simple ideas for composing a lower fat diet & Simple ideas for composing a lower fat diet \\
\hline Hidden fat & A single-day example of how much energy can be saved by being aware of the hidden fat in food \\
\hline Stop feeling hungry ${ }^{a}$ & Sources of complex and refined carbohydrates \\
\hline $\begin{array}{l}\text { How to stop feeling hungry for as long as possible and avoid } \\
\text { longing for sweet food }\end{array}$ & $\begin{array}{l}\text { Explains the part played by mealtime rhythm, and various types of carbohydrates and } \\
\text { proteins in hunger }\end{array}$ \\
\hline Glycaemic index & Definition of the glycaemic index \\
\hline Good routines $^{\mathrm{a}}$ & The importance of a regular mealtime rhythm \\
\hline Parties and having a good time & Ideas for how to tackle parties and celebrations \\
\hline How to succeed & Ideas for how to keep up motivation \\
\hline The motivation ladder & Different stages of a weight-reduction process \\
\hline Use your body ${ }^{\mathrm{a}}$ & Ideas for physical activity \\
\hline Keep moving & Table of energy consumption during different activities \\
\hline Recommended food/menu suggestions & Examples of how much one can eat at different levels of activity \\
\hline For those with diabetes & Advice on diet and physical activity for diabetics \\
\hline Gout & Dietary advice for those with gout \\
\hline Diverse lists of foodstuffs & Overview of the composition of cheese, sauces, cold cuts, savoury spreads and breakfast cereals \\
\hline Seasonal information ${ }^{\mathrm{a}}$ & Dietary ideas and recipes for Christmas, Easter, Lent and summer holidays (low-fat) \\
\hline The appetising plate ${ }^{a}$ & Recipes for low-fat dishes \\
\hline
\end{tabular}

Some of the brochures were sent to all patients (marked ${ }^{\mathrm{a}}$ ), whereas others were sent as needed or at the patient's request.

from protein, $50-55 E \%$ from carbohydrates, of which as much as possible was from complex carbohydrates and as little as possible from refined carbohydrates.

The patient was also encouraged to increase his or her activity level. The targets set were carefully adjusted to suit the individual, but if possible the objective was at least $30 \mathrm{~min}$ of physical activity every day. When the patient had reached the desired weight and/or wanted to stop taking orlistat, it was recommended to reduce the dose gradually. This recommendation was not based on the manufacturer's specifications or clinical trial data, but was considered by the nutritionists to be an aid to prevent sudden weight gain.

\section{Collection of data}

All data were collected on the basis of information from the patients. The data were recorded in an Access database. All the personal information was treated confidentially, and the follow-up system was approved by the Norwegian Data Inspectorate in January 2001. The information in the database was used as a case record by the nutritionist. Statistical calculations on the material in the database were carried out at regular intervals. The length of follow-up was divided into monthly or 3 monthly periods, in order to include all the available followup data. Month 1 was defined as $14-42$ days after start of treatment, month 2 was 43-74 days after start of treatment, month 3 was $2.5-4.5$ months (75-135 days) after start of treatment, month 6 was 4.5-7.5 months (136-225 days) after start of treatment, month 9 was 7.5-10.5 months (226315 days) after start of treatment, month 12 was 10.5-13.5 months (316-405 days) after start of treatment and month 15 was $13.5-16.5$ months (406-515 days) after start of treatment. To investigate whether there were differences between those who stayed in the programme for more or less than 10.5 months, the following statistical methods were used: all continuous variables were analysed using Student's $t$-test and all categorical variables were analysed using the chi-squared test.

\section{Results}

From March 2001 to July 2004, nine nutritionists worked in the follow-up system. From April 2001 to $30^{\text {th }}$ June 2004, 4158 referral cards requesting follow-up were received. Individuals with whom 
the nutritionist failed to make contact or those who did not start taking orlistat were excluded. The remaining material consisted of 3526 patients. The mean age was 41 years (SD 14). Of these, $81.5 \%$ were women and $18.5 \%$ were men. The mean BMI at the start of treatment was 33.7 (SD 9.0). Of the patients, $66.1 \%$ had attempted to lose weight many times before, $27.6 \%$ had made some previous attempts to lose weight and $6.4 \%$ had not tried before. The mean number of orlistat capsules taken per day was 2.8 (SD 0.4).

Patients who were included after November 2002 ( $n=2167$, i.e. $61.5 \%$ of the whole group) were asked whether they had had additional complications of overweight or obesity such as high blood pressure, high cholesterol and type 2 diabetes. These conditions were defined according to whether the referring physician had made the diagnosis. Of these, some did not know their blood pressure $(n=87)$ and/or cholesterol $(n=232)$. Of those who were able to answer, $39.5 \%$ reported high blood pressure, $29.2 \%$ reported high cholesterol and $13.9 \%$ reported type 2 diabetes. Table 2 shows the figures in women and men.

Data were available for 3021 patients $(85.7 \%$ of the group), which was sufficient to establish whether they satisfied the criteria for orlistat according to the text in the Norwegian Pharmaceutical Product Compendium. Most of these, $79.6 \%$ of the women and $89.6 \%$ of the men, satisfied the criteria. The age was $\geq 18$ years and the BMI $\geq 30$ in $76.1 \%$ of the women and $85.0 \%$ of the men. In $3.5 \%$ of the women and $4.6 \%$ of the men, the age was $\geq 18$ years and the BMI $\geq 28$, or the BMI was $<30$ and there was at least one concomitant risk factor such as type 2 diabetes, high total cholesterol or high blood pressure. Reasons for not satisfying these criteria were that $4.8 \%$ of the women had a BMI between 28 and 30 without risk factors; the corresponding figure in men was $1.8 \%$. Furthermore, $10.1 \%$ of the women and $4.1 \%$ of the men had a BMI between 25 and 28 , while $5.1 \%$ of the women and $3.7 \%$ of the men had a BMI below 25 . Only $0.4 \%$ of the women and $0.8 \%$ of the men were under 18 years old.

The mean length of participation in the support programme was 7.2 months (SD 6.3). About $25 \%$ were followed up for 10.5 months or more. Table 3 shows those who were followed up for 10.5 months or more compared with those followed up over a shorter period. Patients who remained in the treatment programme for $\geq 10.5$ months were older $(p<0.01)$ and reported a higher prevalence of risk factors including high blood pressure and high cholesterol $(p<0.01)$ than those who followed the programme for $<10.5$ months. The women who remained in the treatment programme for $\geq 10.5$ months were also more obese than those who followed the programme for $<10.5$ months $(p<0.01)$.

Reasons for dropout in the first 15 months (Table 4) were primarily because the patients stopped taking orlistat $(n=2131$, i.e. $79.9 \%$ of the reported reasons for dropout). Of these, $18.8 \%$ stopped because they thought that orlistat was too

Table 2. Characteristics of the patients

\begin{tabular}{|c|c|c|c|c|}
\hline & Women & $n$ & Men & $n$ \\
\hline Total number & 2873 & & 653 & \\
\hline Age (years) & $39.7(13.7)$ & 2672 & $48.0(13.0)$ & 614 \\
\hline Weight (kg) & $91.4(27.7)$ & 2736 & II 2.7 (30.9) & 612 \\
\hline BMI $\left(\mathrm{kg} \mathrm{m}^{-2}\right)$ & $33.3(5.1)$ & 2660 & 35.1 (8.6) & 590 \\
\hline Follow-up time (months) & $7.1(6.3)$ & 2861 & $7.6(6.5)$ & 650 \\
\hline Number of capsules of orlistat during treatment period & $2.8(0.4)$ & 2710 & $2.8(0.5)$ & 609 \\
\hline$\%$ with no previous attempts to lose weight & 4.8 & 2185 & 14.7 & 422 \\
\hline$\%$ with some previous attempts to lose weight ${ }^{a}$ & 23.4 & 2185 & 49.3 & 422 \\
\hline$\%$ with many previous attempts to lose weight ${ }^{\mathrm{a}}$ & 71.9 & 2185 & 36.0 & 422 \\
\hline$\%$ with high blood pressure & 32.2 & 1682 & 53.5 & 398 \\
\hline$\%$ with high cholesterol & 27.3 & $157 \mid$ & 37.1 & 364 \\
\hline$\%$ with type 2 diabetes & 13.9 & 1765 & 18.2 & 402 \\
\hline
\end{tabular}

Data are given as mean (SD) or as percentages.

$n$ : number of data for each variable.

a "Some previous attempts" was defined as I-9; "many previous attempts" was defined as 10 or more. 
Table 3. Characteristics of patients who stayed in the programme for $\geq 10.5$ months or $<10.5$ months

\begin{tabular}{|c|c|c|c|c|c|}
\hline & $\begin{array}{l}\text { Followed up } \\
<10.5 \text { months }\end{array}$ & $n$ & $\begin{array}{l}\text { Followed up } \\
\geq 10.5 \text { months }\end{array}$ & $n$ & $P$ \\
\hline Number & 2650 & & 876 & & \\
\hline$\%$ of female patients & 75.5 & & 24.5 & & 0.3271 \\
\hline$\%$ of male patients & 73.7 & & 26.3 & & \\
\hline Mean age (years) & $45.6(13.7)$ & 2451 & $49.1(12.8)$ & 835 & $<0.0001$ \\
\hline Weight $(\mathrm{kg})$ at start of treatment, women & $89.4(28.7)$ & 2041 & $97.1(23.3)$ & 695 & $<0.0001$ \\
\hline Weight $(\mathrm{kg})$ at start of treatment, men & III.3 (32.5) & 444 & I I6.I (25.8) & 168 & 0.1919 \\
\hline BMI $\left(\mathrm{kg} \mathrm{m}^{-2}\right)$ at start of treatment, women & $32.7(9.4)$ & 1970 & 35.1 (7.7) & 690 & $<0.0001$ \\
\hline BMI $\left(\mathrm{kg} \mathrm{m}^{-2}\right)$ at start of treatment, men & $34.9(9.0)$ & 424 & $35.6(7.6)$ & 166 & 0.6341 \\
\hline$\%$ with no previous attempts to lose weight & 6.6 & 1865 & 5.7 & 739 & 0.0508 \\
\hline$\%$ with some previous attempts to lose weight & 28.7 & 1865 & 24.6 & 739 & \\
\hline$\%$ with many previous attempts to lose weight & 64.7 & 1865 & 69.7 & 739 & \\
\hline$\%$ with high blood pressure & 36.2 & 1485 & 47.9 & 595 & $<0.0001$ \\
\hline$\%$ with high cholesterol & 27.2 & 1383 & 34.1 & 552 & 0.0027 \\
\hline$\%$ with type 2 diabetes & 13.8 & 1524 & 14.2 & 643 & 0.8083 \\
\hline
\end{tabular}

$n$ indicates the number of data for each variable. Data are given as means (standard deviation) or as percentages.

expensive, $18.7 \%$ because they had reached their weight goal, $14.7 \%$ because of lack of motivation, $12.4 \%$ because the effect of orlistat was less than desired, $8.2 \%$ because of steatorrhoea, $3.5 \%$ because of other adverse effects, $3.7 \%$ because they started other weight-loss programmes, $2.8 \%$ because they were not experiencing further weight loss, 2.1\% because they became pregnant, $1.2 \%$ because they did not receive a new prescription and $13.9 \%$ for other reasons. The remaining dropouts $(n=537$, i.e. $20.1 \%$ of the reported reasons for dropout) were because the patient and/or the nutritionist decided that there was no need for further follow-up (38.1\%) or the patient did not respond to calls or letters from the nutritionist $(61.9 \%)$.

Change in body weight in the patients who reported their weight on at least two occasions, regardless of how long they had been followed up, is shown in Table 4. The material consisted of 2456 patients ( $69.7 \%$ of the whole group), of whom 1998 were women and 458 were men. Patients who were excluded from this material were those who chose not to report their weight (532 women and $122 \mathrm{men}$ ) and/or patients where the follow-up was terminated after a single contact with the nutritionist (109 women and $31 \mathrm{men}$ ) and/or patients (309 women and 54 men) who started taking orlistat too shortly before the last date for this study $\left(30^{\text {th }}\right.$ June 2004), so that the nutritionist had only had time for one consultation with the patient. There are several reasons for data on weight not being available at every occasion in all the patients included in this material. Some patients had not weighed themselves at the time stated, some followups had been terminated before the time stated, and the nutritionist had sometimes not had time for more consultations before the data were collected from the database.

The mean weight reduction in the patients who had been followed up for at least 4.5 months, and who chose to report their weight on at least two occasions $(n=1891)$, was $9.1 \%$ of their original weight just before the follow-up (95\% confidence interval 7.8-10.4). Of the 1992 patients who had at least 4.5 months of follow-up, 101 chose not to report weight. Of the 2456 patients who reported their weight on at least two occasions, $1720(70.0 \%)$ achieved $\geq 5 \%$ weight loss and $807 \quad(32.9 \%)$ achieved $\geq 10 \%$ weight loss.

\section{Discussion}

A clinically significant weight reduction was seen in patients who chose to report their weight at the start of the programme and at a minimum of one follow-up consultation. As the study is only descriptive of the use of orlistat in the context of a support programme, there was no control group who received neither support nor a prescription for orlistat (or only one of the two). As a result, the study does not prove the efficacy of orlistat. In a previously published study from general practice, in which about one-third of the patients took part in a 


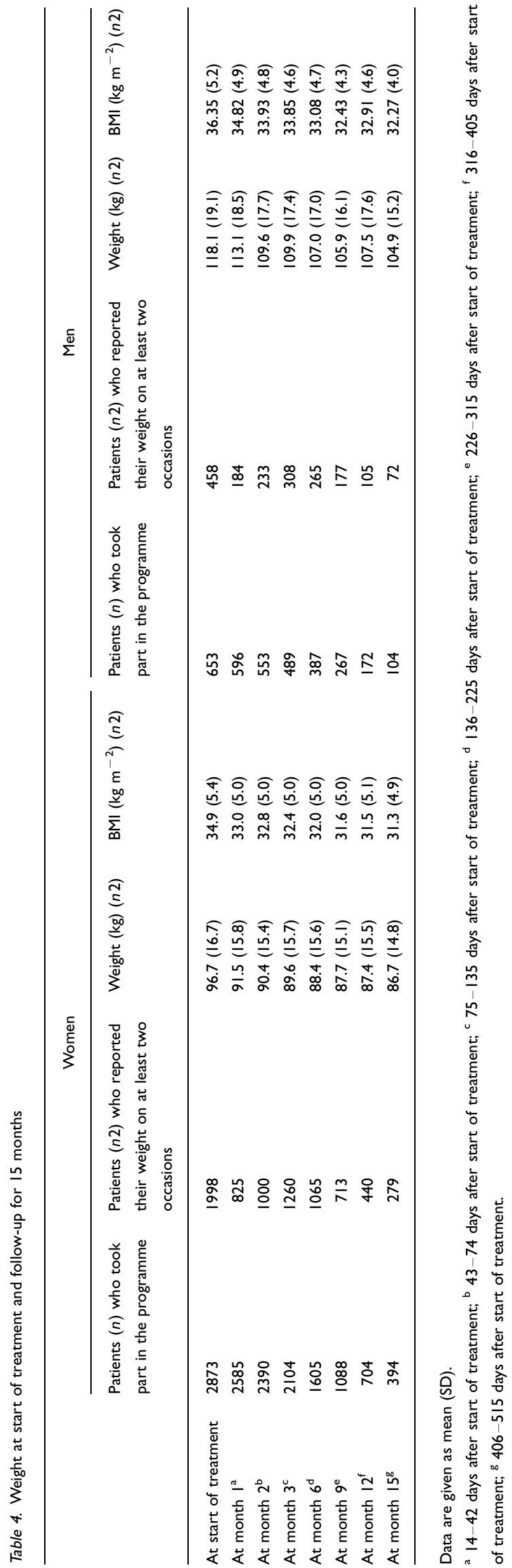

follow-up programme similar to the present one, the mean weight reduction in 15549 users of orlistat was $10.7 \%$ after 7.1 months (11). This effect is close to the one observed in the present programme. A series of randomized controlled clinical trials has previously shown that orlistat is more effective than placebo, and results in clinically beneficial weight reduction in patients with overweight or obesity and their complications of overweight or obesity such as type 2 diabetes and hypertension (12).

An important weakness of the present data is that they are self-reported. However, patients were their own controls. The degree of weight reduction may have been over-reported to the nutritionist who gave the advice. Patients who did not report their weight probably had poorer results than those who chose to report their weight.

The authors are not aware of previous data on whether patients who are prescribed orlistat meet medically accepted criteria for use of the medication. The majority of the patients in the current study satisfied the criteria in the Norwegian Pharmaceutical Product Compendium. Patients with a BMI between 28 and 30 may have had other risk factors than those that they reported.

Orlistat has been approved for treatment for 4 years, but experience has shown that many stop taking it after using it for a short period. Weight may increase again after withdrawing the medication, unless energy intake is further reduced or physical activity is increased. Patients who remained in the treatment programme for 10.5 months or more were more obese and older, and reported a higher prevalence of risk factors than those who followed the programme for less than 10.5 months, indicating that high-risk patients are more likely to adhere to the programme.

A change in lifestyle is an essential element in the treatment of overweight and obesity with or without medication. The mechanism of action of orlistat is directed against fat, which seems to be the most important dietary factor in the treatment of overweight and obesity (13). Changes in diet are essential to achieve weight reduction and avoid side-effects.

Physicians and health personnel are often faced with challenges when giving advice to overweight and obese patients. Lack of time and knowledge about this type of therapy $(14,15)$ limits the amount of help that health professionals are able to give patients who are interested in weight loss. 
The present results show that a support programme may be a useful aid. Given regular follow-up and counselling $(6,15)$, a substantial majority of the patients seem to have reached the treatment target.

\section{Acknowledgements}

We would like to thank the following nutritionists who worked in the follow-up programme: Ellen-Margrethe Hovland, Janne Langehaug Antonsen, Kathrine C Haavardsholm, Merete Helgeland, Siv Tone Natland, Kristin Holvik, Marianne Tronrud and dietary adviser Mette Strøm. We would also like to thank Gunnar Hansen for care of the database, as well as all the physicians who referred patients to the programme. The study was sponsored in its entirety by Roche Norge AS.

Reported conflicts of interest: Kathrin Kobbevik and Unni Gisletun are employed by Roche. Fredrik Hansson is an independent statistical consultant who was paid by Roche for the assignment. Serena Tonstad has received honoraria from Roche, Abbott and other pharmaceutical companies for lectures.

\section{References}

1. Forebygging og behandling av overvekt/fedme i helsetjenesten. Oslo: Sosial- og Helsedirektoratet; 2004.

2. Goldstein DJ. Beneficial health effects of modest weight loss. Int J Obes Relat Metab Disord 1992; 16: 397-415.

3. Torgerson JS, Hauptman J, Boldrin MN, Sjöström L. Xenical in the Prevention of Diabetes in Obese Subjects (XENDOS) study: a randomized study of orlistat as an adjunct to lifestyle changes for the prevention of type 2 diabetes in obese patients. Diabetes Care 2004; 27: 155-61.

4. Mullen PD, Simons-Morton DG, Ramirez G, Frankowski RF, Green LW, Mains DA. A metaanalysis of trials evaluating patient education and counseling for three groups of preventive health behaviors. Patient Educ Couns 1997; 32: 157-73.
5. Nawaz H, Adams ML, Katz DL. Weight loss counseling by health care providers. Am J Public Health 1999; 89: 764-7.

6. Karvetti RL, Hakala P. A seven-year follow-up of a weight reduction programme in Finnish primary health care. Eur J Clin Nutr 1992; 46: 743-52.

7. Tonstad S, Birkeland KI. Fedmeepidemien - har slankepiller en plass i behandlingen? Tidsskr Nor Lægefor 2000; 120: 1997-2001.

8. Stewart M, Brown JB, Weston WW, McWhinney IR, McWilliam CL, Freeman TR. Patient-centered medicine. Transforming the clinical method. Thousand Oaks, CA: Sage; 1995.

9. Pekkarinen M. Methodology in the collection of food consumption data. World Rev Nutr Diet 1970; 12: $145-71$.

10. Norske næringsstoffanbefalinger. Oslo: Statens ernæringsråd; 1997.

11. Wirth A. Reduction of body weight and co-morbidities by orlistat: the XXL-Primary Health Care Trial. Diabetes Obes Metab 2005; 7: 21-7.

12. Padwal R, Li SK, Lau DCW. Long-term pharmacotherapy for obesity and overweight (Cochrane Review). In The Cochrane Library (Issue 1). Oxford: Update Software; 2004.

13. Astrup A, Grunwald GK, Melanson EL, Saris WH, Hill JO. The role of low-fat diets in body weight control: a meta-analysis of ad libitum intervention studies. Int $\mathbf{J}$ Obes 2000; 24: 1545-52.

14. Kushner RF. Barriers to providing nutrition counseling by physicians: a survey of primary care practitioners. Prev Med 1995; 24: 546-52.

15. Williamson DA, Perrin LA. Behavioral therapy for obesity. Endocrinol Metab Clin North Am 1996; 25: 943-54.

\section{Kathrin Kobbevik}

Roche Norge AS

Postbox 4 I Haugenstua

NO-09I5 Oslo

Norway

Tel: +4722789000

Fax: +4722789099

E-mail: kathrin.kobbevik@broadpark.no 